\title{
Development of the very long-range cosmic-ray muon radiographic imaging technique to explore the internal structure of an erupting volcano, Shinmoe-dake, Japan
}

\author{
T. Kusagaya and H. K. M. Tanaka \\ Earthquake Research Institute, The University of Tokyo, 1-1-1 Yayoi, Bunkyo, Tokyo 113-0032, Japan \\ Correspondence to: T. Kusagaya (kusagaya@eri.u-tokyo.ac.jp)
}

Received: 27 April 2015 - Published in Geosci. Instrum. Method. Data Syst. Discuss.: 29 July 2015

Revised: 22 October 2015 - Accepted: 3 November 2015 - Published: 24 November 2015

\begin{abstract}
Muography offers us a tool to observe hazardous erupting volcanoes remotely. However, practical muographic observations of volcanoes from a distance are difficult; therefore, various observations have been performed in the vicinity $(<1.5 \mathrm{~km})$ of volcano peaks to suppress background noise and enhance images. In this study, we created a muographic image directly beneath the caldera floor of the erupting Shinmoe-dake volcano in Japan by locating our muography telescope $5 \mathrm{~km}$ from the peak. The Shinmoe-dake volcano began to erupt on 19 January 2011 and, in less than 1 month, the ejected lava almost completely filled the caldera and completely changed the topography of the caldera floor. The resultant image shows a low-density region underneath the western part of the newly created caldera floor, which indicates the existence of a void there. After the volcano became less active in February 2011, infrequent eruptions might have left a void beneath the caldera floor, which may trigger a collapse in the future. We anticipate that our novel muography will be a practical tool for monitoring and predicting eruption sequences in the near future.
\end{abstract}

\section{Introduction}

To date, one of the keys to successful volcano muography that directly contributes to the understanding of the eruption dynamics has been to shorten the time required for capturing a practical radiographic image of an erupting volcano (Tanaka, 2014). For example, Tanaka et al. (2014) reduced electromagnetic background events by adding redundant detectors and radiation shields to a conventional muography telescope (e.g., Tanaka and Yokoyama, 2013), thereby improving the time resolution. They successfully visualized magma movements with a time resolution of 3 days. The reduction of background events is known to be essential for shortening the measurement time (Tanaka and Yokoyama, 2013).

Another important benefit of muography is that it allows us to observe hazardous volcanoes from a long distance. However, the telescopes have needed to be placed in the vicinity $(0.5-1.6 \mathrm{~km})$ of the volcano craters (Tanaka et al., 2014, 2010b, 2009a, b, 2007a, b; De Lellis et al., 2014; Tanaka and Yokoyama, 2013; Carbone et al., 2013; Kusagaya et al., 2013; Lesparre et al., 2012; Hernández et al., 2013; Miyamoto et al., 2012) (Fig. 1). Although Cârloganu et al. (2013) located their telescope at a distance of $2 \mathrm{~km}$ from the peak of the Puy de Dôme volcano, they reported that the background noise dominated the muon flux when the rock thickness exceeded $1 \mathrm{~km}$. Such short-range muography is practical when the target volcanoes are dormant or less active.

Thus far, there are two examples of muography measurements that targeted erupting volcanoes. In one of the examples, the telescope was buried underground prior to the eruption (Tanaka et al., 2009b), and in the second example the eruption was non-explosive (Tanaka et al., 2014). In the latter case, the volcanic eruption index (VEI) was zero.

In this work, we investigated possibilities of using very long-range muography (VLRM) as an alternative remote sensing tool for volcano monitoring. In conjunction with a newly developed analysis method, we used a lowbackground muography telescope to image the density distri- 


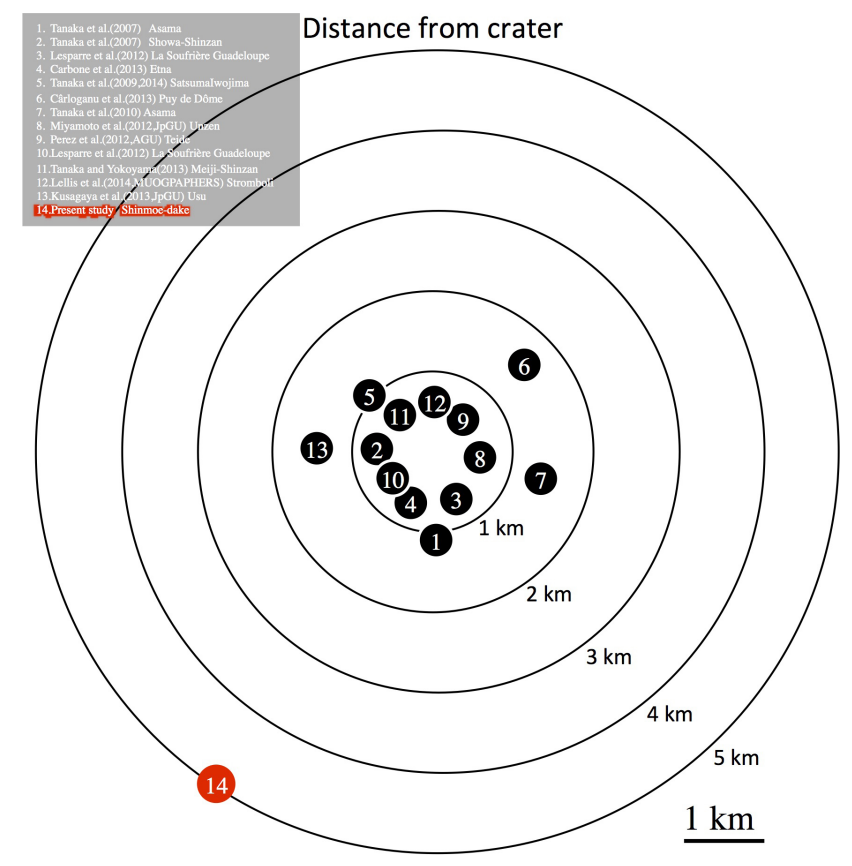

Figure 1. Visual comparison with prior works. The past muography observation sites are plotted as distance from the peak of the volcano.

bution beneath the caldera floor of the Shinmoe-dake volcano in Japan.

The latest eruption of the Shinmoe-dake volcano took place on 19 January 2011. An eruption column reached $3000 \mathrm{~m}$ above sea level on 26 January. A small lava dome (10 $\mathrm{m}$ in diameter) was created on 28 January and continued to grow inside the caldera. On 30 January it almost completely filled the caldera. The Miyazaki Prefecture reported that 1150 people had been evacuated from the area on the same day. At the same time, the area within $3 \mathrm{~km}$ of the mountain was designated as a forbidden zone. On 2 February a volcanic bomb reached beyond this restriction line. It reached $3.2 \mathrm{~km}$ from the peak of the mountain (Japan Meteorological Agency, 2013). The amount of magma discharged between 19 January and 2 February was estimated to be 2.7$3.7 \times 10^{6} \mathrm{~m}^{3}$ (VEI 2). Since 2011, the Japan Meteorological Agency (JMA) volcano eruption levels remained high and were at Level 2 in 2014. People are forbidden to approach the volcano any closer than approximately $1 \mathrm{~km}$ from the crater when the JMA volcano eruption level is at Level 2.

In this work, we installed our muon telescope at a distance of $5 \mathrm{~km}$, south of the center of the caldera, for the purpose of investigating a 2011 Shinmoe-dake eruption. We report our successful VLRM, which exhibits a low-density region below the Shinmoe-dake caldera floor that might cause the caldera to collapse in the future.

\section{Principle}

\subsection{Muography}

In this section, we briefly introduce the principle of muography. To measure the internal density distribution of a volcano, the integrated flux of cosmic-ray muons before and after passing through the volcano is compared. Primary cosmic rays, which predominantly consist of protons, arrive at the top of Earth's atmosphere and generate muons as a consequence of interaction with atmospheric nuclei. A number of past experiments have measured the cosmic-ray muon energy spectrum at sea level (e.g., Achard et al., 2004; Haino et al., 2004; Allkofer et al., 1985; Jokisch et al., 1979). Although there are systematic differences between them, the average energy of muons tends to be higher at larger zenith angles. For instance, while the integrated vertical muon flux $\left(0^{\circ}\right.$ from zenith) is $7 \times 10^{-3}$ and $5 \times 10^{-8} \mathrm{~cm}^{-2} \mathrm{sr}^{-1} \mathrm{~s}^{-1}$ above $1 \mathrm{GeV}$ and $1 \mathrm{TeV}$, respectively (Beringer et al., 2012), the horizontal flux $\left(85^{\circ}\right.$ from zenith) is $1 \times 10^{-4}$ and $1.6 \times$ $10^{-7} \mathrm{~cm}^{-2} \mathrm{sr}^{-1} \mathrm{~s}^{-1}$ above $1 \mathrm{GeV}$ and $1 \mathrm{TeV}$, respectively (Allkofer et al., 1985). For the purpose of interpolating the measured flux, several groups have formulated approximate equations of the muon energy spectrum as a function of energy and zenith angle (e.g., Gaisser, 2002; Matsuno et al., 1984; Smith and Duller, 1959). However, the systematic difference between them ranges from 10 to $100 \%$ (Lesparre et al., 2010).

The interaction of muons with matter is also well known. The energy loss of muons through matter is given as a function of density length (density $\times$ path length along the muon path) and several approximation methods have been attempted (e.g., Barrett et al., 1952). Monte Carlo (MC) simulations offer more accurate results (Groom et al., 2001). The minimum energy of muons that can penetrate a given thickness of rock can be derived based on these calculations. For example, $1 \mathrm{TeV}$ muons can penetrate matter with a thickness of $2.5 \mathrm{~km}$ water equivalent. Therefore, the integrated muon flux after passing through a mountain can be calculated by integrating the energy flux over the range between this minimum energy and infinity (Fig. 2). While there is a general tendency for muons to be more strongly attenuated as the rock becomes thicker, the vertical muons are attenuated more strongly than the horizontal muons. Because the target's path length information can be exploited from a topographic map, the average density can be derived along the muon paths. Muography offers images of volcano interiors with a higher spatial resolution than possible with conventional geophysical measurements.

\subsection{Very long-range muography}

When performing VLRM, background sources that are unique to this method must be considered. 


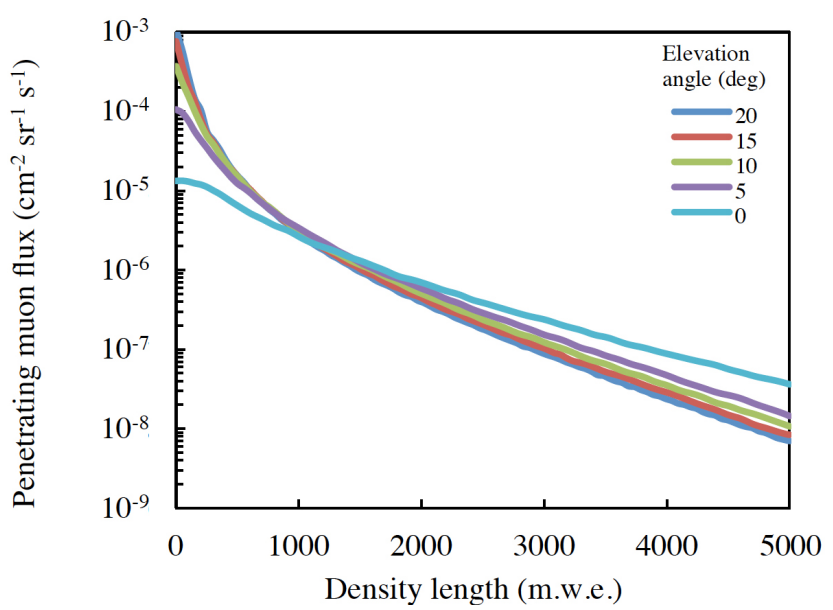

Figure 2. Elevation angle dependence on muon flux after passing through a given rock thickness. The rock thickness is given in units of meter water equivalent (m.w.e.).

\subsubsection{Muon decay}

A muon decays into an electron (a positron) and two neutrinos within a lifetime $\left(\tau_{\mu}\right)$ of $2.2 \mu \mathrm{s}$. The decay length $(L)$ of relativistic muons is given by

$L=\gamma \tau_{\mu} c$

where $\gamma$ is the Lorentz gamma factor, and $c$ is the speed of light. As can be calculated in Eq. (1), the muon survival probability tends to be lower when muons travel longer. For example, $15 \%$ of muons with an energy of $1 \mathrm{GeV}$ decay after traveling $1 \mathrm{~km}$ in a vacuum but $56 \%$ decay after traveling $5 \mathrm{~km}$. The secondary electrons (positrons) due to muon decay are called decay electrons (decay positrons).

\subsubsection{Scattering of decay electrons in the atmosphere}

As the distance between the target and muography observation site becomes longer, the atmospheric density length increases and thus decay electrons are scattered more often and lose their initial directions. The typical length in which the Bremsstrahlung process takes place is called the radiation length $\left(X_{0}\right)$, and $X_{0}$ for an electron is $303.9 \mathrm{~m}$ in a $1 \mathrm{~atm}$ atmosphere. When the distance that a muon has traveled is much longer than its non-relativistic decay length $(660 \mathrm{~m})$ and $X_{0}$ for an electron, the muon will decay, and its decay electron will experience many Bremsstrahlung processes and will deviate from the original muon's path. Because muons are 207 times heavier than electrons, muons do not experience Bremsstrahlung processes in the atmosphere within this distance scale.

Figure 3 shows the results of extended air-shower Monte Carlo (MC) simulations. A MC code called Cosmos (Kasahara and Cohen, 2008) was used to reproduce the energy spectrum of the electromagnetic (EM) components (electron

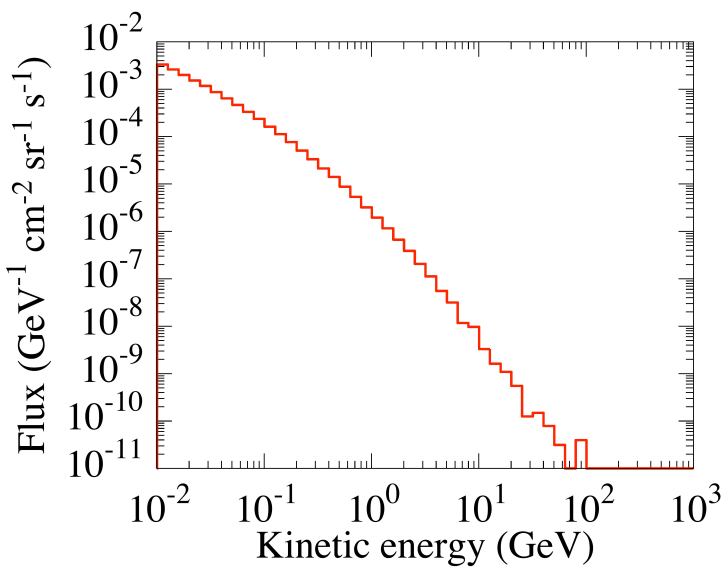

Figure 3. Differential energy spectrum of electromagnetic components (electron and positron) of secondary cosmic rays at sea level. The arriving angles range between 50 and $90^{\circ}$ from zenith.

and positron) arriving from the zenithal angle region between 50 and $90^{\circ}$ at sea level. In these simulations, $9.5 \times 10^{8}$ primary particles with an energy range between $260 \mathrm{MeV}$ and $260 \mathrm{TeV}$ (Beringer et al., 2012) were injected at the top of Earth's atmosphere. The top five elements $(\mathrm{H}, \mathrm{He}, \mathrm{C}, \mathrm{N}$, and O) were selected as primary particles. These particles were injected into the atmosphere isotropically within an angle range of $0-95^{\circ}$ from zenith.

In Fig. 3, the differential flux is plotted within an energy range between $10 \mathrm{MeV}$ and $1 \mathrm{TeV}$. Electrons with energies above $10 \mathrm{MeV}$ can penetrate a $5 \mathrm{~cm}$ thick plastic scintillator; thus, these components could be background sources when thin plastic scintillators (e.g., Lesparre et al., 2012) or gaseous detectors (e.g., Cârloganu et al., 2013; Oláh et al., 2012) are used for muography observations. If the angular resolution of a muography telescope is not enough to distinguish these components from muons, these electrons and positrons scatter in the air, change direction, and become a possible source of background events. The EM fluxes integrated over the energy range above $10 \mathrm{MeV}$ and $1 \mathrm{GeV}$ are $9.4 \times 10^{-5}$ and $1.7 \times 10^{-6} \mathrm{~cm}^{-2} \mathrm{sr}^{-1} \mathrm{~s}^{-1}$, respectively. These values are equivalent to the muon flux (arriving at $85^{\circ}$ from zenith) after passing through 100 and $1200 \mathrm{~m}$ of water, respectively.

\section{Methods}

\subsection{Muography telescope}

Our muography telescope is described in detail in a separate paper (Tanaka et al., 2014); therefore, we briefly introduce our apparatus in this section. The telescope had an active area of $1.5 \times 1.5 \mathrm{~m}^{2}$. A position sensitive plane (PSP) was comprised of adjacent horizontal and vertical scintillation counters with $10 \mathrm{~cm}$ wide plastic scintillator strips (ELJEN EJ- 
200) and photomultiplier tubes (PMT) (Hamamatsu R7724), which formed a segmented plane. Simultaneous signal outputs from the horizontal and vertical scintillation counters indicated where the charged particle traversed the PSP. Our muography telescope consisted of six PSPs. The first and sixth PSPs were separated by $3.0 \mathrm{~m}$, so that an angular interval of $33 \mathrm{mrad}$ was achieved. Herein, we defined the axes that were vertical to the ground and perpendicular to the PSP as the $y$ and $z$ axes, respectively, and the axis that was perpendicular to both the $y$ and $z$ axes as the $x$ axis.

The background noise by fake tracks is created by the accidental coincidence of vertical EM components (Tanaka and Yokoyama, 2013). To reduce such events, a telescope with six PSPs was designed in this work. Even if EM components hit all PSPs, the vertex points are expected to form a random alignment. Thus, such events are expected to be removed by selecting linear trajectory for reducing the background by fake tracks.

As seen in Fig. 3, shielding electrons with energies below $100 \mathrm{GeV}$ is essentially equivalent to removing the entire horizontal EM background. For this reason, five $10 \mathrm{~cm}$ thick lead plates $(50 \mathrm{~cm}$ in total) were inserted between each of the six PSPs. Because the radiation length of lead for an electron is $5.6 \mathrm{~mm}$ (Beringer et al., 2012), the size, weight and cost of the radiation shield can be minimized. However, because the lead plates were deformable, we concealed each plate in a $3 \mathrm{~cm}$ thick stainless steel case (Fig. 4).

To test if our telescope could practically remove all EM components, the number of electrons that stopped inside a lead block was investigated using the Geant 4 MC code (Agostinelli et al., 2003) for particle propagation. Figure 5 shows the number of secondary electrons generated inside a lead shield as a function of depth from the surface. In total, 100 electrons with energies of $100 \mathrm{GeV}$ were injected. The number of secondary electrons increased quickly but eventually decreased at a depth of $50 \mathrm{~mm}$ from the surface, and they almost disappeared deeper than $450 \mathrm{~mm}$ from the surface. A total of $4_{-2}^{+3}$ electrons remained within a depth region between 400 and $450 \mathrm{~mm}$, and they completely disappeared at greater depths than this region.

We muographically imaged the Shinmoe-dake volcano, located in the Kagoshima and Miyazaki prefectures in Japan. The altitudes at our muography telescope and the caldera floor before and after the 2011 eruption were 610, 1240, and $1350 \mathrm{~m}$, respectively (Fig. 6, Shimono et al., 2011). Subsequent to the eruption, no significant changes to the topography of the caldera floor have been reported. We installed our muography telescope $5 \mathrm{~km}$ south of the center of the Shinmoe-dake caldera (Fig. 7). Therefore, the elevation angles of the caldera floor before and after the eruption were 128 and $150 \mathrm{mrad}$, respectively. We defined an azimuth angle of $0 \mathrm{mrad}$ in the direction of the center of the caldera. The angular interval (Tanaka et al., 2010a) of the telescope was $\pm 33 \mathrm{mrad}$; therefore, the telescope could capture the magma deposit beneath the present caldera floor within a

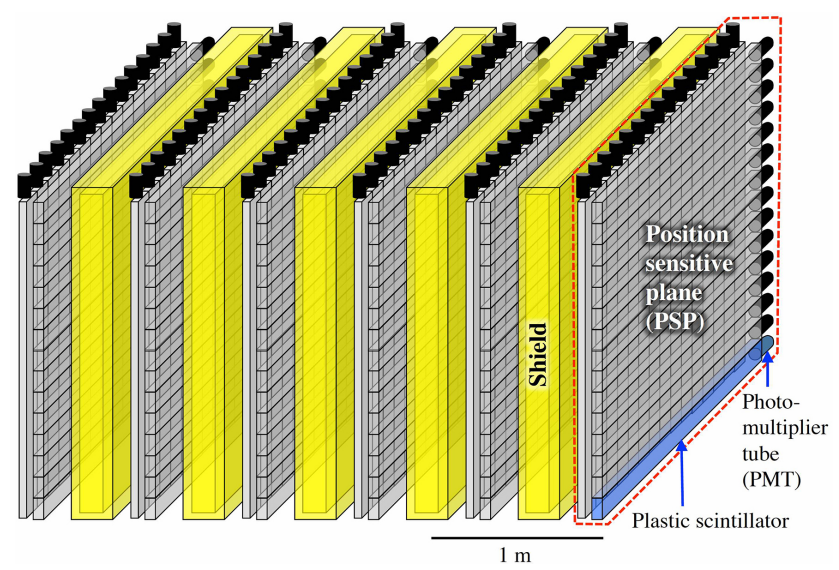

Figure 4. Schematic of the muography telescope used for the present work.

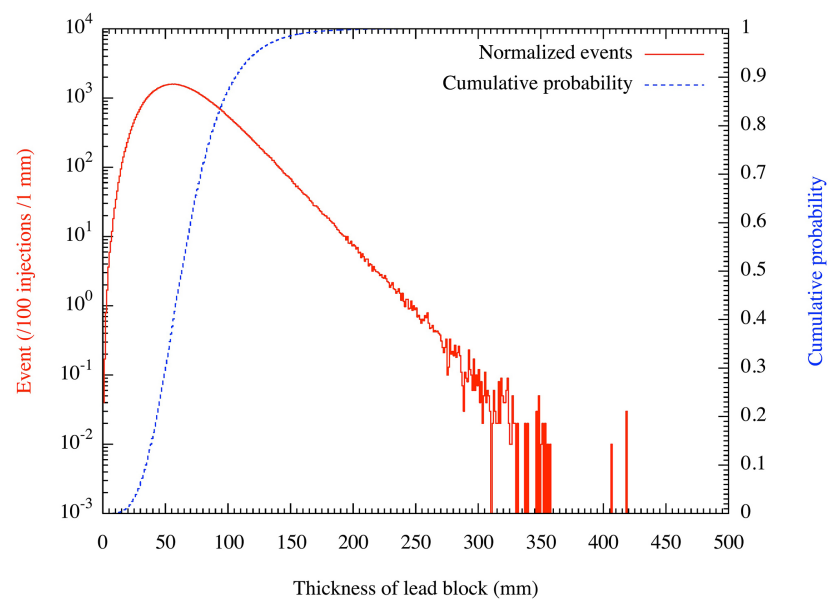

Figure 5. Distribution of the electrons stopped inside a lead block. The incident energy is $100 \mathrm{GeV}$. The stopping probability per $1 \mathrm{~mm}$ at different depths (red) and the corresponding cumulative probability (blue) are shown.

$131 \pm 33 \mathrm{mrad}$ range of elevation angles. Figure 8 shows the path length distribution of Shinmoe-dake as a function of elevation and azimuth angles. As seen in this figure, path lengths exceeded $5000 \mathrm{~m}$ in the region below the $100 \mathrm{mrad}$ elevation angle. It was difficult for us to image this region with our present telescope. The measurements began on 10 October 2014 and continued until 4 November 2014. The observational duration was 64 days.

\subsection{Analysis}

\subsubsection{Muon tracking}

The directions of the incident particles in the telescope can be determined by connecting two vertex points in the first and the last position sensitive planes (PSP\#1 and \#6). For muon 

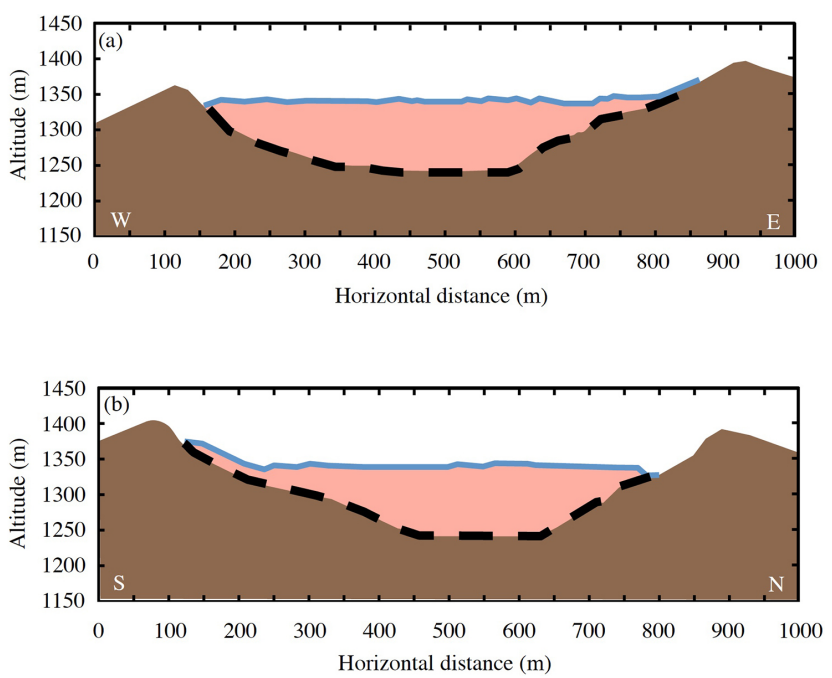

Figure 6. Caldera deformation captured with airborne synthetic aperture radar (SAR) measurements. The black dotted and blue solid lines, respectively, show the topography of the caldera floor before (March 2009) and after (February 2011) the 2011 eruption for the west-east cross section (a) and south-north cross section (b).

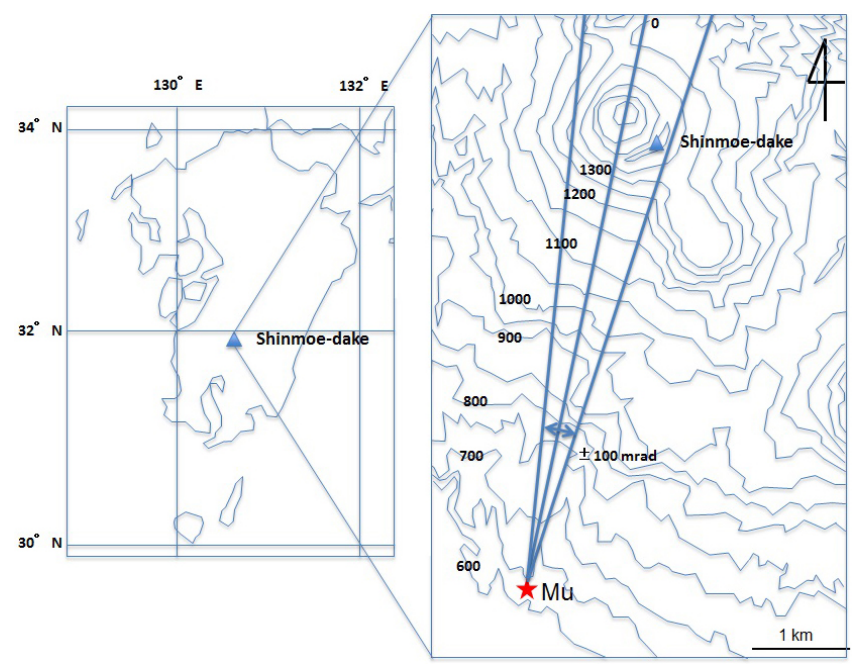

Figure 7. Geometrical configuration of the experimental setup. The left panel shows the location of the Shinmoe-dake volcano. The right panel shows an enlarged map in the vicinity of the Shinmoedake volcano. The muography telescope $(\mathrm{Mu})$ was located $5 \mathrm{~km}$ south-southwest from the center of the Shinmoe-dake volcano caldera. The topographic map does not reflect the land deformation during the 2011 eruption.

tracking, we selected straight trajectories for incident events according to the following process.

a. When an event was detected in all six PSPs within a time window of $40 \mathrm{~ns}$, the vertex points in PSP\#1 and \#6 were recorded.
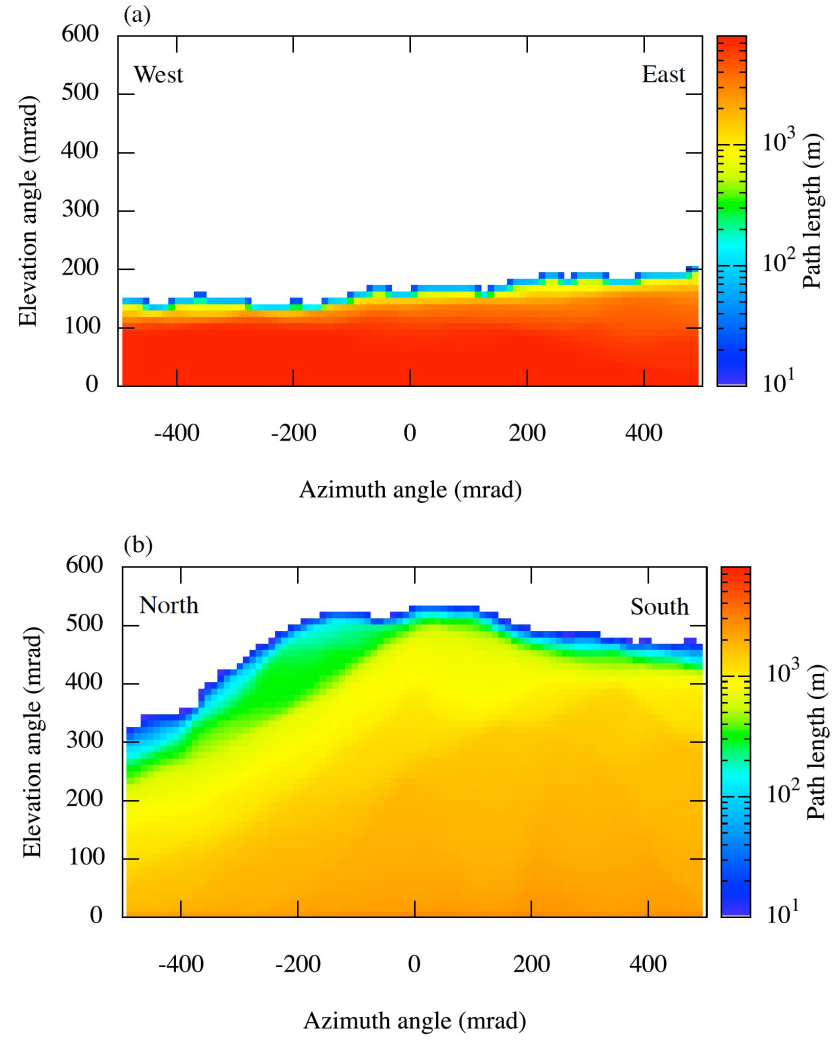

Figure 8. Path length distribution of volcanoes viewed from different distances. The solid angle when viewing a larger volcano (Shinmoe-dake) (a) is smaller than that when viewing a smaller volcano (Satsuma-Iwo Jima) (b) if the distance to the target is farther.

b. When two or more events were detected in a single PSP within a time window of $40 \mathrm{~ns}$, these events were not recorded (Tanaka et al., 2001).

c. When the vertex points in the redundant PSPs, i.e., PSPs \#2-5, deviated within $\pm N$ segments ( $N$ value) from the straight line created by connecting the vertex points in (a), event tracks were generated. Smaller $N$ values gave better tracking linearity.

Figure 9 illustrates our tracking scheme for $N=1$. Figure 10 shows the number of recorded open-sky event tracks that survived for different $N$ values. Because we could not identify the location of the vertex points within the scintillator strip, the telescope failed to track some events if only linear trajectories were selected $(N=0)$. The figure also shows that the number of muons scattered at large angles in the telescope was negligible because there are no significant variations for $N>2$.

Figure 11 shows the maximum deviations of the Geant4simulated vertex points in 4 redundant PSPs (i.e., PSPs \#25) from a linear trajectory drawn by connecting the vertex points in PSPs \#1 and \#6. For these simulations, muons were injected into the virtual telescope, which is identical to the 

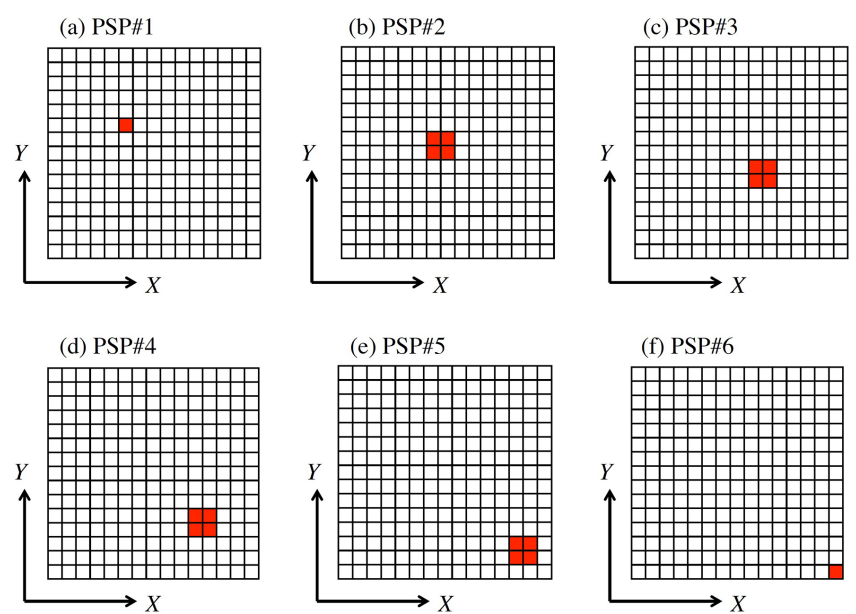

Figure 9. Example of muon tracking for $N=1$. If a signal (a red square) is generated at $(x, y)=(5,10)$ in PSP \#1 (a) and at $(x, y)=$ $(15,1)$ in PSP \#6 (f) simultaneously, the signal generation points (red squares) in PSPs \#2-5 (b-e) are used for tracking.

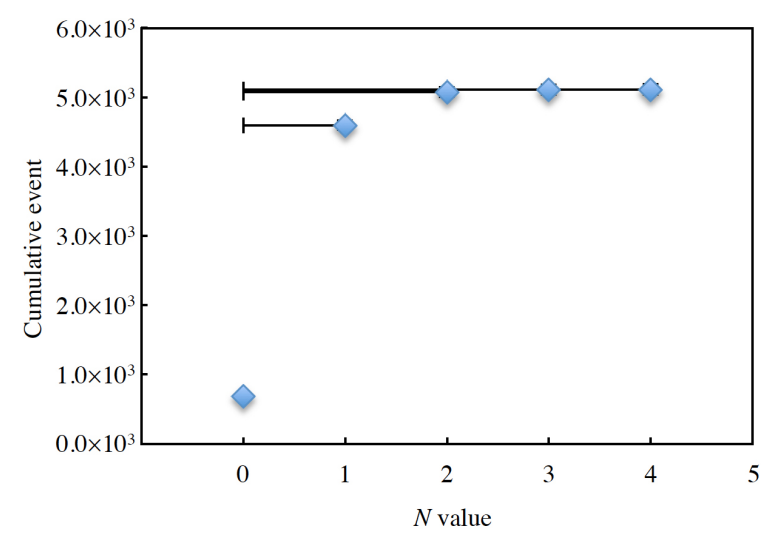

Figure 10. Number of event tracks as a function of $N$. Error bars indicate the range of integration.

actual telescope, with an energy spectrum of $70^{\circ}$ from zenith. The plot in Fig. 11 is consistent with the $N$ dependence on the recorded number of tracks (Fig. 10), and we therefore conclude that the event tracks recorded with our telescope using the just-discussed tracking scheme were muon tracks. We specified $N=1$, because large $N$ values blur the resultant image.

\subsubsection{Background estimation}

To analyze long-range muography data, we developed an alternative analysis method to solve the following problems that were not addressed in prior works.

a. As described in Sect. 2.2, when a muon travels long distances, the muon decay process cannot be neglected. Because the radiation lengths of decay electrons/positrons are short $(309 \mathrm{~m})$, there is a high proba-

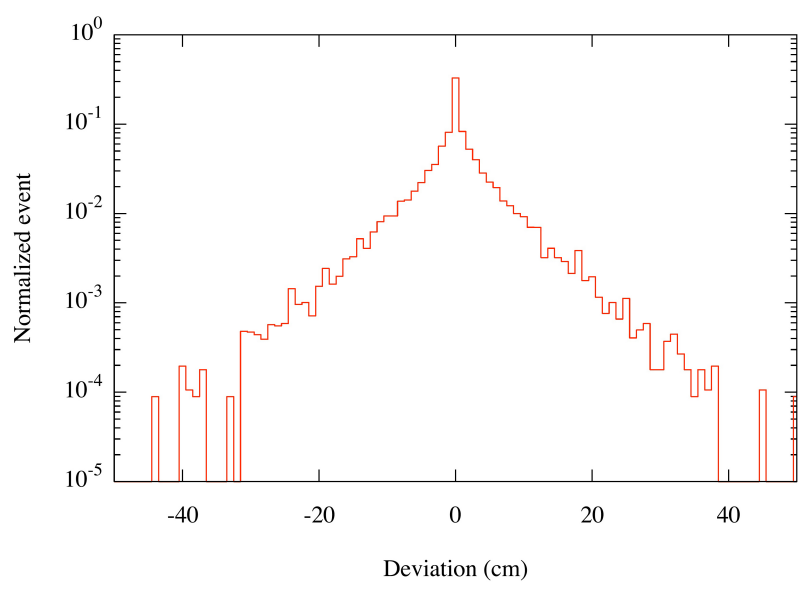

Figure 11. Muon scattering inside the telescope. The event was normalized to the total number of events.

bility that they will experience multiple Bremsstrahlung processes and that the muon's initial direction therefore will be lost. We confirmed that a sufficiently thick lead shield $(50 \mathrm{~cm})$ would eliminate those EM backgrounds.

b. Muons scatter inside the telescope. We must consider two different types of muon sources regarding their incident directions (because we do not distinguish forward-directed muons from backward-directed muons): (i) muons arriving from above the ridge of the mountain (the forward direction) and (ii) those from the opposite side of the mountain (the backward direction).

c. For long-range muography (LRM), a mountain tends to be smaller in angular space. For example, as shown in Fig. 8, while the elevation angle of a peak $(700 \mathrm{~m}$ relative height) is $500 \mathrm{mrad}$ for short-range $(1.2 \mathrm{~km}) \mathrm{muog}$ raphy (SRM) (Tanaka et al., 2014), the elevation of a taller mountain's peak $(750 \mathrm{~m}$ relative height) is only $150 \mathrm{mrad}$ for long-range $(5 \mathrm{~km})$ muography (the present work). This means that near-horizontal muons are utilized more with LRM.

When we consider factors (b) and (c), a tracking problem unique to LRM arises. Firstly for (i), in general, relativistic muon scattering is very small and negligible for SRM. For example, muons that scatter more than $200 \mathrm{mrad}$ after passing through the radiation shield are $0.001 \%$ of the total; thus, scattered open-sky muons will not contaminate tracks from the region of interest. However, for LRM, this effect becomes serious. Muons that scatter more than $100 \mathrm{mrad}$ after passing through the radiation shield are $0.1 \%$ of the total. Likewise for (ii), as long as the region of interest is located at high elevations, the scattering of backward-directed muons is negligible. However, for LRM, because the region of interest is usually located at low elevations, this effect also becomes serious. 
To estimate muon scatterings inside the telescope, MC simulations (Geant4) were performed. In these simulations, 500000 muons were injected into the modeled radiation shields $(50 \mathrm{~cm}$ thick lead and $30 \mathrm{~cm}$ thick stainless steel plates) according to an energy spectrum measured within an angle range between 60 and $70^{\circ}$ from zenith (Achard et al., 2004; Tsuji et al., 1998; Abdel-Monem et al., 1975). The lowest muon energy considered in the simulation was $1 \mathrm{GeV}$, which corresponded to the cutoff energy derived from the detectors and the shields. Figure 12 shows the scattering angle distribution of near-horizontal muons after they passed through the radiation shields. While approximately $4 \%$ of the muons scattered at angles greater than $33 \mathrm{mrad}$, only $0.7 \%$ of the muons scattered at angles greater than $100 \mathrm{mrad}$. These numbers correspond to scattered muon fluxes of $\sim 10^{-6} \mathrm{~cm}^{-2} \mathrm{sr}^{-1} \mathrm{~s}^{-1}$ if we assume that the arriving angle of the muons was $80^{\circ}$. These are likely orders of magnitude estimates.

To estimate the background level from muon scattering inside the telescope, we calculated the flux of muons that scattered towards the telescope's $y$ direction. The elevation angle dependence on the number of background events $N_{\mathrm{BG}}(\theta)$ measured within the elevation angle range from $\theta$ to $\theta+\Delta \theta$ is

$N_{\mathrm{BG}}(\theta)=\int N(\theta) P(\theta) \mathrm{d} \theta$,

where $\Delta \theta$ is an angular interval of our detector, and $N(\theta)$ is the elevation angle dependence on the number of muons measured within an elevation angle range from $\theta$ to $\theta+\Delta \theta$. $P(\theta)$ is given by

$P(\theta)=\frac{\int_{\theta}^{\theta+\Delta \theta} \phi(\theta) \mathrm{d} \theta}{\int_{0}^{\infty} \phi(\theta) \mathrm{d} \theta}$,

where $\phi(\theta)$ is the muon scattering probability distribution function shown in Fig. 12.

The elevation angle dependence on the forward-directed and backward-directed background event flux is plotted in Fig. 13 by calculating Eq. (2). Because low energy muons tend to scatter inside the telescope, the recorded background events were reduced by selecting near-linear trajectories, depending on the $N$ value. Figure 13 also shows the background event flux for a selection criterion of $N=1$.

\section{Results}

\subsection{Comparison between different muography ranges}

To study the effect of the muography range, we compared muography data collected at different distances from volcanoes. For comparison, data collected at the Satsuma-Iwo Jima volcano were reanalyzed because the data were collected using the same type of the detector $1.4 \mathrm{~km}$ from the peak. Figure 14 shows the dependence of the event flux on

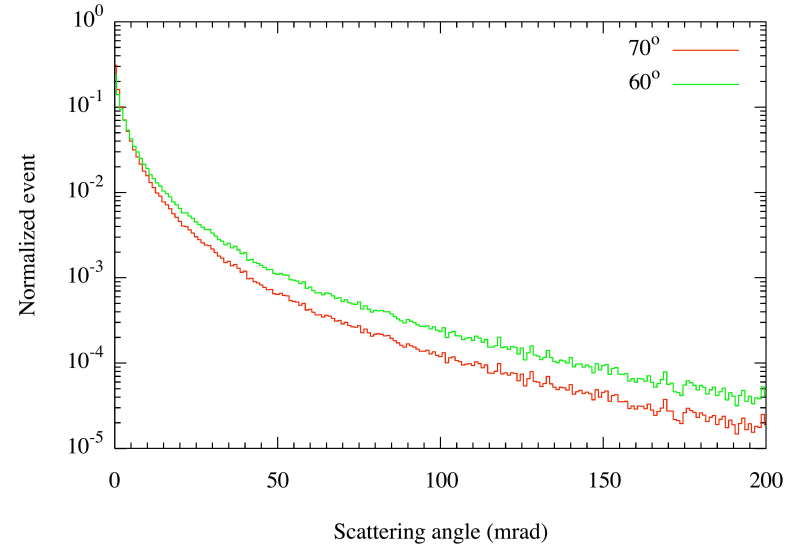

Figure 12. Scattering angle distribution of near-horizontal muons. The events are normalized by the total number of muons that were injected.

(a)

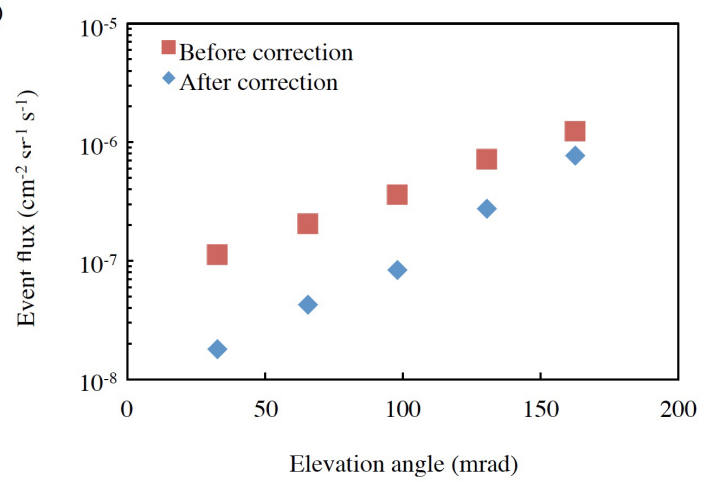

(b)

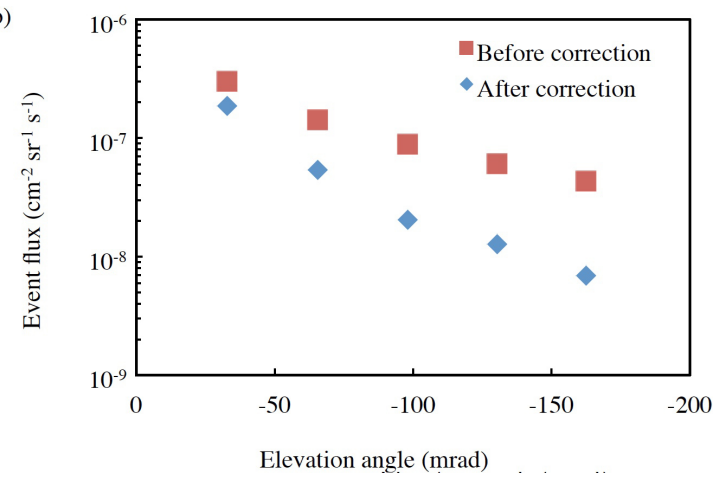

Figure 13. Elevation angle dependence on background event flux. The background levels are expected to be measured for different elevation angles with the telescope and are plotted for the events arriving from the direction of the target mountain (a) and from the side opposite to the mountain (b). The plot also shows the background event flux before (red squares) and after (blue diamonds) selecting linear trajectories from these events with a selection criterion of $N=1$.

elevation angle for Satsuma-Iwo Jima (blue dots in Fig. 14) and Shinmoe-dake (red dots in Fig. 14). Firstly, we found that the elevation angle dependencies on the backward-directed 


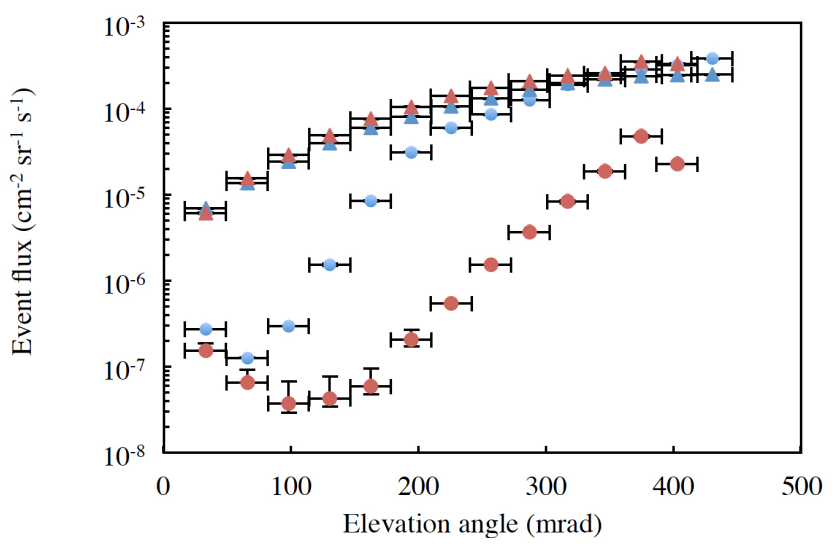

Figure 14. Elevation angle dependence on averaged event flux observed at Shinmoe-dake and Satsuma-Iwo Jima. The flux was averaged between azimuth ranges from -430 to $430 \mathrm{mrad}$ for Shinmoedake and from 0 to $400 \mathrm{mrad}$ for Satsuma-Iwo Jima. The backwarddirected (open sky) and forward-directed (mountain side) flux is shown for Shinmoe-dake and Satsuma-Iwo Jima with blue and red triangles and blue and red circles, respectively.

event fluxes were comparable. Because there was mostly open sky opposite to the mountains at both locations, we expect that these data will be similar. Secondly, we found that the muon counts $1.5_{-0.2}^{+0.3} \times 10^{-7} \mathrm{~cm}^{-2} \mathrm{sr}^{-1} \mathrm{~s}^{-1}$ recorded at Satsuma-Iwo Jima did not show the minimum value at an elevation angle of $33 \mathrm{mrad}$, even though the target thickness was a maximum $(>2000 \mathrm{~m})$ in this direction. The expected muon flux is $1 \times 10^{-8} \mathrm{~cm}^{-2} \mathrm{sr}^{-1} \mathrm{~s}^{-1}$ there. Likewise, the observed flux at an elevation angle of $66 \mathrm{mrad}$ was $6.5_{-0.9}^{+2.8} \times 10^{-8} \mathrm{~cm}^{-2} \mathrm{sr}^{-1} \mathrm{~s}^{-1}$, while the expected muon flux is $2 \times 10^{-8} \mathrm{~cm}^{-2} \mathrm{sr}^{-1} \mathrm{~s}^{-1}$. This deviation is caused by the backward-directed horizontal muons that were scattered in our radiation shields, as described in Sect. 3.2.2. As shown in Fig. 15, the theoretically estimated $N_{\mathrm{BG}}(\theta)$ for $N=1$ (Fig. 13b) explains the excess of forward-directed event fluxes at low elevation angles (33 and $66 \mathrm{mrad}$ ).

On the other hand, while the Shinmoe-dake and Iwo Jima fluxes were similar at elevation angles of 33 and $66 \mathrm{mrad}$, the Shinmoe-dake flux was systematically higher than the Iwo Jima flux at elevation angles larger than $100 \mathrm{mrad}$. There are two possible reasons for this deviation: (a) the thickness of the rock at Shinmoe-dake is thinner than at SatsumaIwo Jima or (b) background events offset the data. The path lengths of the muons at Shinmoe-dake ranged from 5000 to $7000 \mathrm{~m}$ within the angular region. The corresponding flux was $\sim 10^{-10} \mathrm{~cm}^{-2} \mathrm{sr}^{-1} \mathrm{~s}^{-1}$; therefore, (a) can be rejected. Because the ridge of Shinmoe-dake is located at an elevation angle of approximately only $200 \mathrm{mrad}$, even small muon scatterings inside the telescope could appear to be more horizontal muon events from the direction below the ridge. Therefore, the possible background sources were the sum of the (a) forward-directed and (b) backward-directed

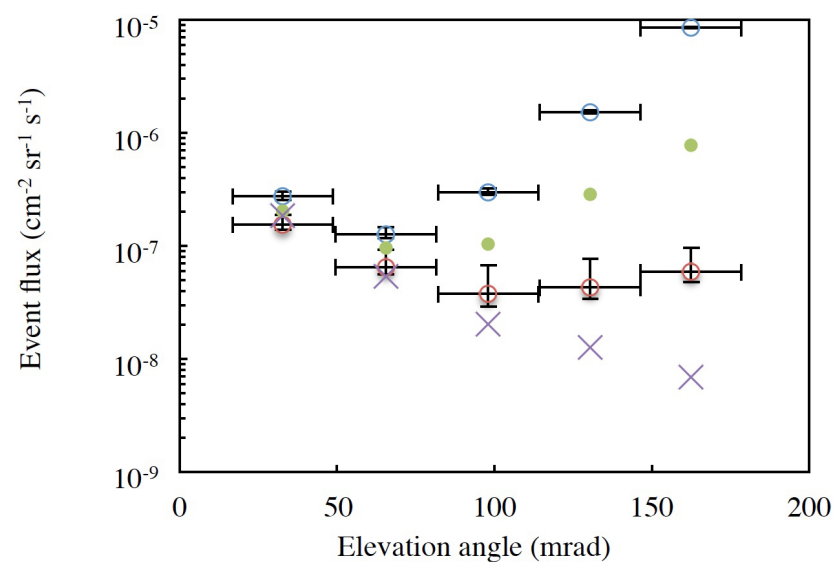

Figure 15. Comparison of the measured and theoretical background fluxes. The blue and red circles show the elevation angle dependence on the Shinmoe-dake and Iwo Jima fluxes, and the purple crosses and green circles show the estimated background from backward-directed muons and both forward and backward-directed muons, respectively.

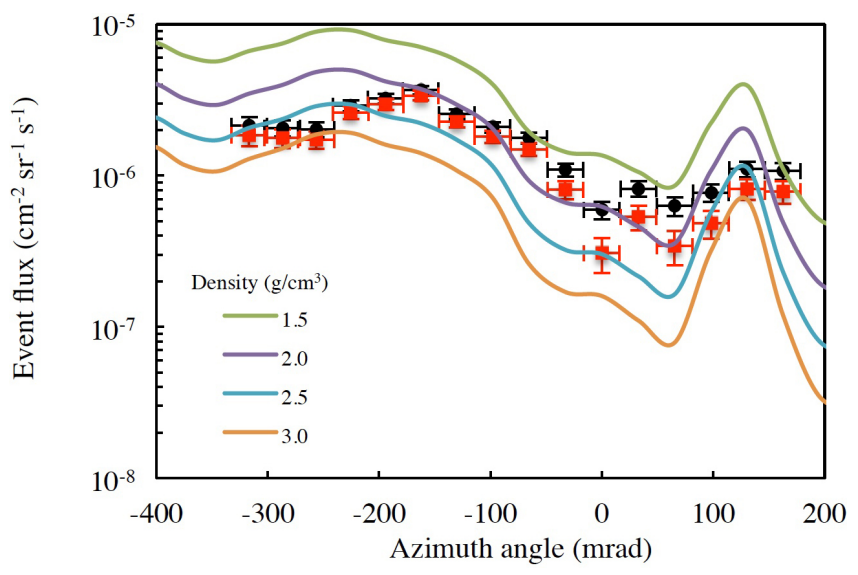

Figure 16. Azimuth distribution of event flux measured at the Shinmoe-dake volcano. The data collected at the elevation angle of $130 \mathrm{mrad}$ are plotted along with the theoretical flux calculated for different density values $\left(1.5,2.0,2.5\right.$, and $\left.3.0 \mathrm{~g} \mathrm{~cm}^{-3}\right)$. The data before (black squares) and after (red squares) the background event removal are plotted.

muon scatterings inside the detector. Figure 15 compares the elevation angle dependence on the Shinmoe-dake flux with the sum of the forward- and backward-directed background event fluxes $N_{\mathrm{BG}}(\theta)$ for $N=1$. As seen in this figure, the excess of the Shinmoe-dake flux at lower elevation angles (33 and $66 \mathrm{mrad}$ ) can be explained by these backgrounds. The difference between the Shinmoe-dake flux and $N_{\mathrm{BG}}(\theta)$ at elevation angles larger than $100 \mathrm{mrad}$ was recognized from muons after passing through the volcano. 

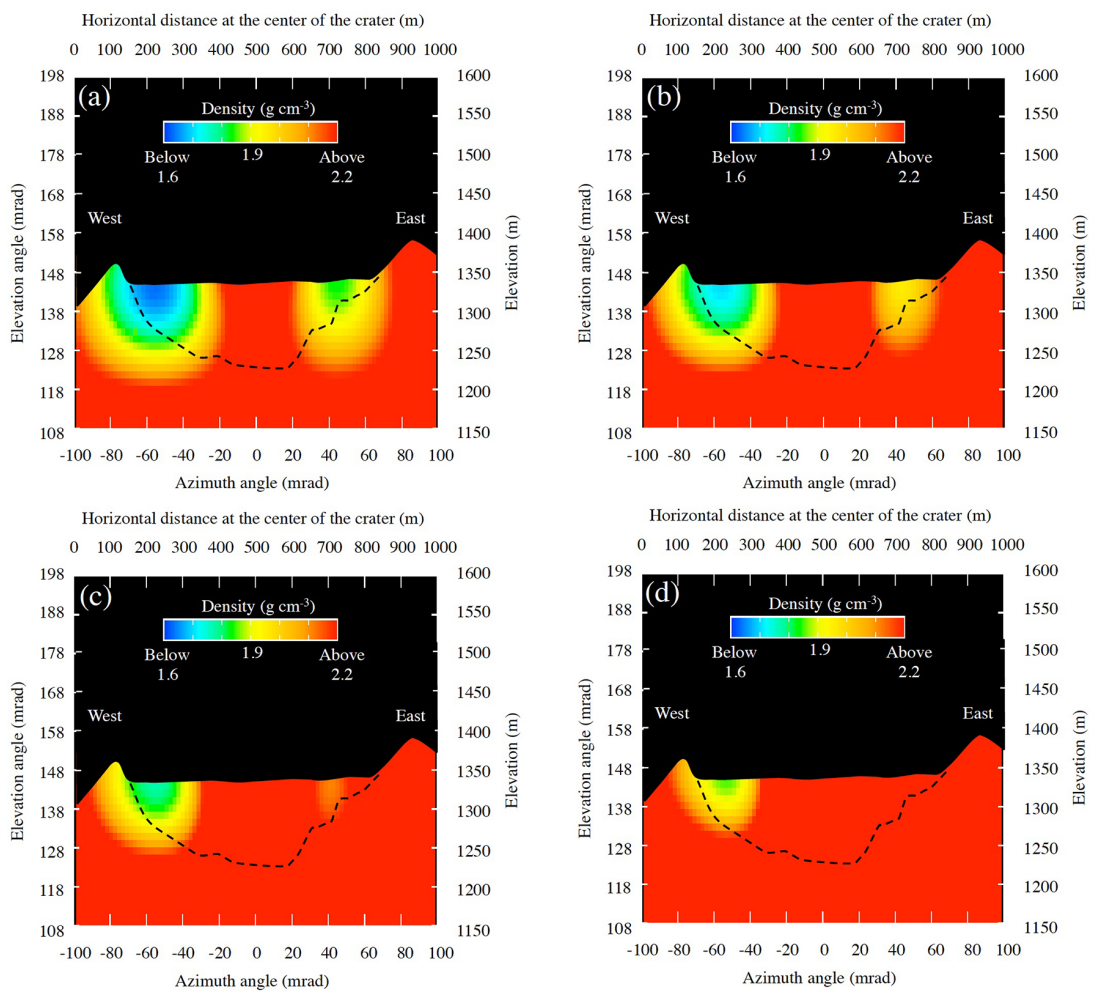

Figure 17. Interpolated muographic images showing (a) mean densities, (b) $1 \sigma$, (c) $2 \sigma$, and (d) $3 \sigma$ upper limit densities below the Shinmoedake caldera floor. The east-west cross sections of the mountain before (dotted lines) and after the 2011 eruption (February 2011) are shown. The color scale shows the average density along the muon paths.

\subsection{Very long-range muographic imaging of the Shinmoe-dake volcano}

To derive the average density along the muon paths passing through a region right below the caldera floor, in Fig. 16 we compared the theoretical and experimental Shinmoe-dake muon fluxes at an elevation angle of $130 \mathrm{mrad}$ as a function of azimuth angle $(\phi)$. In this figure, only the data points with more than 50 events were plotted. For $\phi<-350 \mathrm{mrad}$ and $\phi>200 \mathrm{mrad}$, the numbers of events were less than 50 because (a) the active areas of the telescope were small and (b) the rock became thick.

\section{Discussion}

Figure 17 shows muographic images below the Shinmoedake caldera. These images were produced by interpolating the discrete data points for the purpose of enhancing the visual effect. In this image, because we did not record sufficient number of events below the caldera floor before the 2011 eruption, we modeled the density in this region by applying the average density of the crater rim. In Fig. 17, an east-west cross section in the region of the mountain peak is also plotted to show the profile of the caldera before and after the 2011 eruption. To illustrate the statistical significance of the density contrast, the $1 \sigma, 2 \sigma$, and $3 \sigma$ upper limits of the density are plotted in Fig. 17b-d, respectively. As seen in Fig. 17, the density is sensitive to variations of the sigma values at an elevation angle of $100 \mathrm{mrad}$. This means that the statistical error is large; therefore, there is a large uncertainty in the density values in this region.

As seen in Fig. 17, there are two low-density regions below the present caldera floor. The regions are localized at the eastern and western areas, while the central area has higher densities. Figure 18 shows the location of a crater of an explosive eruption (subplinian event) and a growing lava dome found on the caldera floor on the morning of 28 January 2011 (Nakada et al., 2013). A series of eruptions in 2011 at Shinmoe-dake started from this crater.

Figure 19 shows the results of airborne synthetic aperture radar (SAR) measurements in February and October 2011 (Kobayashi et al., 2013). Figure 19 shows the vertical cross sections along the lines shown in Fig. 18. As seen in this figure, the southeast part of the caldera floor collapsed some time between February and October 2011. The size of the collapse was $100 \mathrm{~m}$ in diameter and $30 \mathrm{~m}$ in depth; however, the depth may have been greater. The location of the collapse coincides with that of the steam vent shown in Fig. 18.

In the present analysis, the caldera topography measured in February 2011 was utilized to derive the average density 


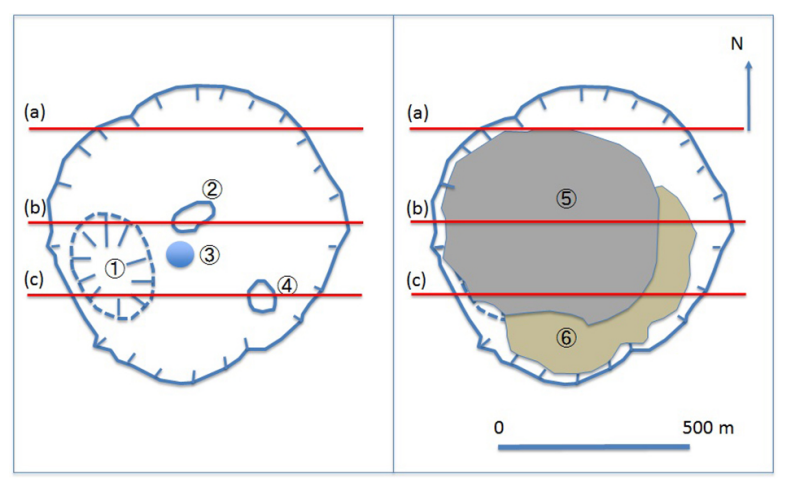

Figure 18. Schematic of the Shinmoe-dake caldera after the 2011 eruption (Nakada et al., 2013). The left and right panels, respectively, show the caldera immediately after the eruption (28 January 2011) and after more than a year had passed (the summer of 2012). The numbers in the plot indicate the following: 1 , a vent of subplinian events; 2 , a vent of continuous emission of fine ash; 3 , a lava dome; 4, a steam vent; 5 , the limit of lava accumulation; and 6, altered, thickly deposited ash. The vertical cross sections are plotted along three red horizontal lines (a, b, and $\mathbf{c})$ in Fig. 19.

along the muon paths. This means that the $100 \mathrm{~m}$ diameter collapse was not incorporated into our analysis, and the muographic images shown in Fig. 17 would reflect this newly created vertical channel. When considering that the typical path length in this region is $\sim 1000 \mathrm{~m}$, the reduction in density would be $\sim 10 \%$. This reduction could explain the lowdensity region found in the eastern part of the caldera. However, there were large density errors in this region; therefore, the contrast was not as apparent (the density contrast disappears when we take the $3 \sigma$ upper limit of the determined density; Fig. 17d).

Unlike the eastern part, the topography of the western part of the caldera floor seems more stable and did not change between February and October 2011 (Fig. 19). However, muographic images show a distinct low-density region immediately below the western caldera floor (Fig. 17). As a consequence, the following scenario can explain the sequence of the 2011 Shinmoe-dake eruption. Lava and ash emitted from the Shinmoe-dake caldera almost filled it over less than a month after the first eruption on 19 January 2011, which took place in the western part of the caldera. After the volcano became less active at the end of February, the more fragile part inside the caldera (i.e., the layer of thickly deposited ash shown in Fig. 18) collapsed right above a steam vent (Fig. 18) and created a $100 \mathrm{~m}$ diameter vertical channel. On the other hand, a lava layer covered an initial subplinian event crater (Fig. 18), and hotter and more fluid magma underneath the solidified surface (that is more stable than deposited ash) was gradually drained into the crater. As a consequence, a lowdensity (porous) region was created underneath the western caldera floor.
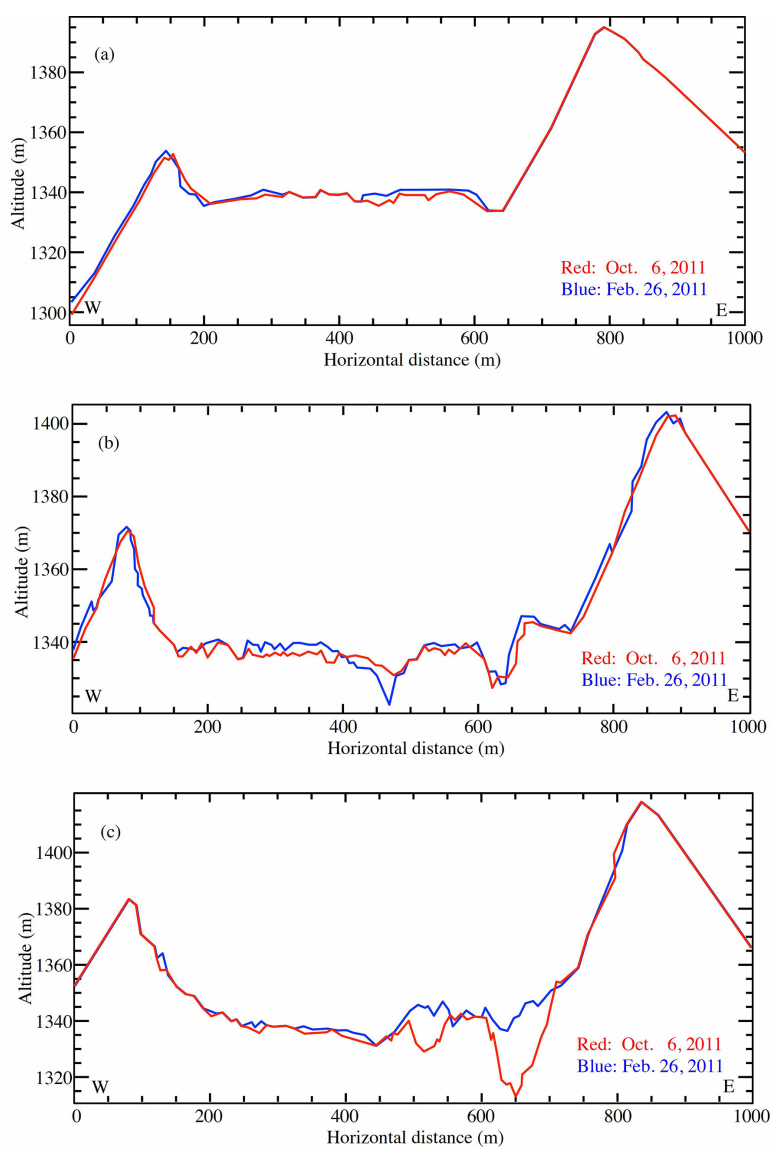

Figure 19. Vertical cross sections inside the caldera of the Shinmoedake volcano along the lines (a), (b) and (c), respectively, in Fig. 18 on 6 October 2011 (red) and 26 February 2011 (blue) by airborne SAR (Pi-SAR2) measurements (Kobayashi et al., 2013).

In prior works, it was reported that a void was created beneath the caldera floor of the Miyake-jima volcano in 2000. The day after the June 8 eruption, an ellipsoidal region with a length of $\sim 700 \mathrm{~m}$ and width of $\sim 400 \mathrm{~m}$ collapsed $\sim 200 \mathrm{~m}$ in depth (Nakada et al., 2001). The precursor of the caldera collapse was detected by gravimetric measurements 2 days prior to the event. Furuya et al. (2001) compared the spatiotemporal changes between 2 days and 2 years before the collapse. A difference in gravity values between those times was $-145 \mu \mathrm{gal}$ inside the caldera, and the data points showed that the values below $-100 \mu$ gal were located within a region $1.0-1.5 \mathrm{~km}$ from the caldera center. A gravity change of $-145 \mu \mathrm{gal}$ corresponds to an upheaval of several tens of centimeters. However, such an upheaval was not detected using Global Positioning System (GPS) measurements. Furuya et al. (2001) interpreted this inconsistency as a new void that formed underneath the crater floor during the 2000 Miyakejima eruption.

In the present work, muography measurements were carried out at a distance of $5 \mathrm{~km}$ from the volcano summit. This implies that VLRM can provide us with a new tool to predict 
caldera collapse by mapping out the density distribution directly beneath the caldera floor. On 8 October 2014 , it was reported that Shinmoe-dake began to deform because of an accumulation of magma beneath the volcano (Geospatial Information Authority of Japan, 2014) that had reached the same level of expansion that was observed right before the 2011 Shinmoe-dake eruption. In future, joint muographic and absolute gravimetric measurements can provide more useful information for predicting volcano eruption sequences by independently measuring magma movements in shallow regions compared to movements in deeper regions. Such measurements can give us new information about magma dynamics inside volcanoes.

\section{Conclusions}

In this work, we successfully applied a calorimeter-type muography telescope with radiation shields and redundant detectors (PSPs) to an erupting volcano for very long-range muography (VLRM). Conventional muography is limited to the vicinity of a volcanic crater, and it is therefore impractical to apply conventional techniques when monitoring erupting volcanoes. Our results show that muography has the potential to be a practical tool for monitoring hazardous volcanic eruptions.

Entry to the summit area of Shinmoe-dake volcano is still restricted. Since the beginning of the 2011 eruption, the surface phenomena associated with eruption transitions have been revealed by airborne and land-based measurements. However, it has been technically difficult to image the internal structure of the volcano from a secure distance. Using VLRM, we found a low-density region directly below the caldera floor, which implies that magma dynamics occurred below the caldera floor after eruptions became less active in February 2011. The location of the low-density region is coincident with the crater that was formed during the initial eruption in January 2011. The void might cause a caldera collapse.

Our present proof-of-principle (POP) work shows the capability of conducting muographic measurements $5 \mathrm{~km}$ from the summit. This is considered to be a safe distance for many volcanic eruptions. On the other hand, for muography applied to erupting volcanoes, precise topographic information of the target is required because the surface topography of an erupting volcano varies with time. Such information can be obtained using repeated airborne synthetic aperture radar (SAR) measurements. In conjunction with recent progress in those airborne techniques, the range of application of muography can be remarkably expanded.

Acknowledgements. We are grateful to two anonymous referees for their valuable comments, which greatly improved this paper.

Edited by: M. Díaz-Michelena

\section{References}

Abdel-Monem, M. S., Benbrook, J. R., Osborne, A. R., Sheldon, W. R., Choate, L. M., Magnuson, C. E., Duller, N. M., and Green, P. J.: Cosmic ray muon spectra at zenith angles $65^{\circ}$ and $80^{\circ}$ using the AMH Magnetic Spectrometer, in: 14th International Cosmic Ray Conference, München, 15-29 August 1975, 6, p. 2043, 1975.

Achard, P., Adriani, O., Aguilar-Benitez, M., et al.: Measurement of the atmospheric muon spectrum from 20 to $3000 \mathrm{GeV}$, Phys. Lett. B, 598, 15-32, doi:10.1016/j.physletb.2004.08.003, 2004.

Agostinelli, S., Allison, J., Amako, K., et al.: Geant4 a simulation toolkit, Nucl. Instrum. Meth. A, 506, 250-303, doi:10.1016/S0168-9002(03)01368-8, 2003.

Allkofer, O. C., Bella, G., Dau, W. D., Jokisch, H., Klemke, G., Oren, Y., and Uhr, R.: Cosmic ray muon spectra at sea-level up to $10 \mathrm{TeV}$, Nucl. Phys. B, 259, 1-18, doi:10.1016/05503213(85)90294-9, 1985.

Barrett, P. H., Bollinger, L. M., Cocconi, G., Eisenberg, Y., and Greisen, K.: Interpretation of cosmic-ray measurements far underground, Rev. Mod. Phys., 24, 133-178, 1952.

Beringer, J., Arguin, J.-F., Barnett, R. M., et al.: Review of particle physics, Phys. Rev. D, 86, 010001 , doi:10.1103/PhysRevD.86.010001, 2012.

Carbone, D., Gibert, D., Marteau, J., Diament, M., Zuccarello, L., and Galichet, E.: An experiment of muon radiography at Mt Etna (Italy), Geophys. J. Int., 196, 633-643, doi:10.1093/gji/ggt403, 2013.

Cârloganu, C., Niess, V., Béné, S., Busato, E., Dupieux, P., Fehr, F., Gay, P., Miallier, D., Vulpescu, B., Boivin, P., Combaret, C., Labazuy, P., Laktineh, I., Lénat, J.-F., Mirabito, L., and Portal, A.: Towards a muon radiography of the Puy de Dôme, Geosci. Instrum. Method. Data Syst., 2, 55-60, doi:10.5194/gi-2-55-2013, 2013.

De Lellis, G., Consiglio, L., Strolin, P., et al.: Muon radiography with nuclear emulsions: stromboli and other projects, in: MUOGRAPHERS2014, Tokyo, 2014.

Furuya, M., Okubo, S., Tanaka, Y., Sun, W., Watanabe, H., Oikawa, J., and Maekawa, T.: Caldera formation process during the Miyakejima 2000 volcanic activity detected by spatio-temporal gravity changes, Journal of Geography (Chigaku Zasshi), 110, 217-225, 2001.

Gaisser, T. K.: Semi-analytic approximations for production of atmospheric muons and neutrinos, Astropart. Phys., 16, 285-294, doi:10.1016/S0927-6505(01)00143-8, 2002.

Geospatial Information Authority of Japan: Press release on 08 October, available at: http://www.gsi.go.jp/WNEW/ PRESS-RELEASE/2014-goudou1008.html, last access: 16 December 2014.

Groom, D. E., Mokhov, N. V., and Striganov, S. I.: Muon stopping power and range tables $10 \mathrm{MeV}-100 \mathrm{TeV}$, Atom Data Nucl. Data, 78, 183-356, doi:10.1006/adnd.2001.0861, 2001.

Haino, S., Sanuki, T., Abe, K., et al.: Measurements of primary and atmospheric cosmic-ray spectra with the BESS-TeV spectrometer, Phys. Lett. B, 594, 35-46, doi:10.1016/j.physletb.2004.05.019, 2004.

Hernández, I., Hernández, P., Pérez, N., Tanaka, H., Miyamoto, S., Barrancos, J., and Padrón, E.: Application of emulsion imaging system for cosmic-ray muon radiography to explore the internal structure of Teide and Cumbre Vieja volcanoes in the Canary 
Islands, Spain, EGU General Assembly, Vienna, Austria, 7-12 April 2013, EGU2013-953, 2013.

Japan Meteorological Agency: Press release on 3 February, available at: http://www.jma.go.jp/jma/press/1102/03a/ yochiren 110203.html and http://scholar.google.com/scholar?hl= en\&btnG=Search\&q=intitle:No+Title\#0, last access: 15 December 2014, 2013.

Jokisch, H., Carstensen, K., Dau, W., Meyer, H., and Allkofer, O.: Cosmic-ray muon spectrum up to $1 \mathrm{TeV}$ at 75degree zenith angle, Phys. Rev. D, 19, 1368-1372, doi:10.1103/PhysRevD.19.1368, 1979.

Kasahara, K. and Cohen, F.: A new parallel processing scheme enabling full Monte Carlo EAS simulation in the GZK Energy Region, in: 30th International Cosmic Ray Conference, 4, 581-584, available at: http://adsabs.harvard.edu/abs/2008ICRC....4...581K, last access: 15 December 2014, 2008.

Kobayashi, T., Umehara, T., Uemoto, J., and Satake, M.: Volcanic monitoring by polarimetric and interferometric airborne SAR (Pi-SAR2), in: 2013 Asia-Pacific Conference on Synthetic Aperture Radar (APSAR), Tsukuba, 23-27 September 2013, 487490, 2013.

Kusagaya, T., Tanaka, H., Taketa, A., Maekawa, T., and Yokoyama, I.: Development of a multifold segmented muon detection system to improve the maximum resolvable distance of muography, Japan Geoscience Union Meeting, Chiba, Japan Geoscience Union Meeting, Japan Geoscience Union, 19-24 May 2013, SVC48-06, 2013.

Lesparre, N., Gibert, D., Marteau, J., Déclais, Y., Carbone, D., and Galichet, E.: Geophysical muon imaging: feasibility and limits, Geophys. J. Int., 183, 1348-1361, doi:10.1111/j.1365246X.2010.04790.x, 2010.

Lesparre, N., Gibert, D., Marteau, J., Komorowski, J.-C., Nicollin, F., and Coutant, O.: Density muon radiography of La Soufrière of Guadeloupe volcano: comparison with geological, electrical resistivity and gravity data, Geophys. J. Int., 190, 1008-1019, doi:10.1111/j.1365-246X.2012.05546.x, 2012.

Matsuno, S., Kajino, F., Kawashima, Y., Kitamura, T., Mitsui, K., Muraki, Y., Ohashi, Y., Okada, A., Suda, T., Minorikawa, Y., Kobayakawa, K., Kamiya, Y., Nakamura, I., and Takahashi, T.: Cosmic-ray muon spectrum up to $20 \mathrm{TeV}$ at $89^{\circ}$ zenith angle, Phys. Rev. D, 29, 1-23, doi:10.1103/PhysRevD.29.1, 1984.

Miyamoto, S., Bozza, C., Ambrosio, N. D., De Lellis, G., Nakamura, M., Rescigno, R., Russo, A., Shimizu, H., Sirignano, C., Stellacci, S., Strolin, P., Tanaka, H., and Tioukov, V.: The first radiography result of the latest lava dome in Unzen by cosmic muons, EGU General Assembly, Vienna, Austria, 22-27 April 2012, EGU2012-1938-1, 2012.

Nakada, S., Nagai, M., Yasuda, A., Shimano, T., Geshi, N., Ohno, M., Akimasa, T., Kaneko, T., and Fujii, T.: Chronology of the Miyakejima 2000 eruption: characteristics of summit collapsed crater and eruption products, Journal of Geography, 110, 168$180,2001$.

Nakada, S., Nagai, M., Kaneko, T., Suzuki, Y., and Maeno, F.: The outline of the 2011 eruption at Shinmoe-dake (Kirishima), Japan, Earth Planets Space, 65, 475-488, doi:10.5047/eps.2013.03.016, 2013.

Oláh, L., Barnaföldi, G. G., Hamar, G., Melegh, H. G., Surányi, G., and Varga, D.: CCC-based muon telescope for examination of natural caves, Geosci. Instrum. Method. Data Syst., 1, 229-234, doi:10.5194/gi-1-229-2012, 2012.

Shimono, T., Minami, H., Nishii, Y., Ohno, H., and Watanabe, K.: Observation of volcanic crater of Mt. Kirishima (Shinmoedake) by Airborne SAR, Bulletin of the GSI (Geospatial Information Authority of Japan), 121, 189-194, 2011.

Smith, J. A. and Duller, N. M.: Effects of pi meson decayabsorption phenomena on the high-energy mu meson zenithal variation near sea level, J. Geophys. Res., 64, 2297, doi:10.1029/JZ064i012p02297, 1959.

Tanaka, H. K. M.: Particle geophysics, Annu. Rev. Earth Pl. Sc., 42, 535-549, doi:10.1146/annurev-earth-060313-054632, 2014.

Tanaka, H. K. M. and Yokoyama, I.: Possible application of compact electronics for multilayer muon high-speed radiography to volcanic cones, Geosci. Instrum. Method. Data Syst., 2, 263273, doi:10.5194/gi-2-263-2013, 2013.

Tanaka, H. K. M., Nagamine, K., Kawamura, N., Nakamura, S. N., Ishida, K., and Shimomura, K.: Development of the cosmic-ray muon detection system for probing internalstructure of a volcano, Hyperfine Interact., 138, 521-526, doi:10.1023/A:1020843100008, 2001.

Tanaka, H. K. M., Nakano, T., Takahashi, S., Yoshida, J., Takeo, M., Oikawa, J., Ohminato, T., Aoki, Y., Koyama, E., Tsuji, H., and Niwa, K.: High resolution imaging in the inhomogeneous crust with cosmic-ray muon radiography: the density structure below the volcanic crater floor of Mt. Asama, Japan, Earth Planet. Sc. Lett., 263, 104-113, doi:10.1016/j.epsl.2007.09.001, 2007a.

Tanaka, H. K. M., Nakano, T., Takahashi, S., Yoshida, J., Ohshima, H., Maekawa, T., Watanabe, H., and Niwa, K.: Imaging the conduit size of the dome with cosmic-ray muons: the structure beneath Showa-Shinzan Lava Dome, Japan, Geophys. Res. Lett., 34, L22311, doi:10.1029/2007GL031389, 2007b.

Tanaka, H. K. M., Uchida, T., Tanaka, M., Shinohara, H., and Taira, H.: Cosmic-ray muon imaging of magma in a conduit: degassing process of Satsuma-Iwojima Volcano, Japan, Geophys. Res. Lett., 36, 1-5, doi:10.1029/2008GL036451, 2009a.

Tanaka, H. K. M., Uchida, T., Tanaka, M., Takeo, M., Oikawa, J., Ohminato, T., Aoki, Y., Koyama, E., and Tsuji, H.: Detecting a mass change inside a volcano by cosmic-ray muon radiography (muography): first results from measurements at Asama volcano, Japan, Geophys. Res. Lett., 36, L17302, doi:10.1029/2009GL039448, 2009b.

Tanaka, H. K. M., Uchida, T., Tanaka, M., Shinohara, H., and Taira, H.: Development of a portable assembly-type cosmicray muon module for measuring the density structure of a column of magma, Earth Planets Space, 62, 119-129, doi:10.5047/eps.2009.06.003, 2010a.

Tanaka, H. K. M., Taira, H., Uchida, T., Tanaka, M., Takeo, M., Ohminato, T., Aoki, Y., Nishiyama, R., Shoji, D., and Tsuji, H.: Three-dimensional computational axial tomography scan of a volcano with cosmic ray muon radiography, J. Geophys. Res., 115, B12332, doi:10.1029/2010JB007677, 2010b.

Tanaka, H. K. M., Kusagaya, T., and Shinohara, H.: Radiographic visualization of magma dynamics in an erupting volcano, Nature Communications, 5, 3381, doi:10.1038/ncomms4381, 2014.

Tsuji, S., Katayama, T., Okei, K., Wada, T., Yamamoto, I., and Yamashita, Y.: Measurements of muons at sea level, J. Phys. G Nucl. Partic., 24, 1805-1822, doi:10.1088/09543899/24/9/013, 1998. 